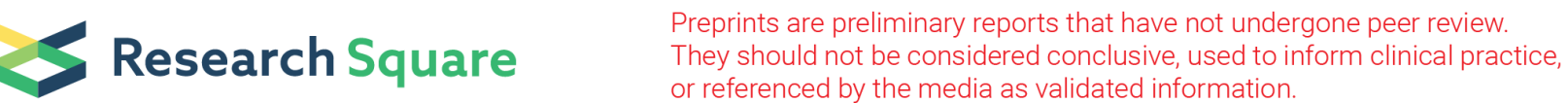

\section{Prevalence and factors associated with pelvic organ prolapse among women attending the gynecology outpatient clinic at a tertiary hospital in southwestern Uganda}

RODGERS TUGUME ( $\nabla$ rodgerstugume@gmail.com )

Mbarara University of Science and Technology Faculty of Medicine https://orcid.org/0000-0001-67286312

Henry Mark Lugobe

Mbarara University of Science and Technology Faculty of Medicine https://orcid.org/0000-0001-81778786

\section{Paul Kalyebara Kato}

Mbarara University of Science and Technology Faculty of Medicine

Rogers Kajabwangu

Mbarara University of Science and Technology Faculty of Medicine https://orcid.org/0000-0003-4101011X

\section{Hamson Kanyesigye}

Mbarara University of Science and Technology Faculty of Medicine

\section{Sezalio Masembe}

Mbarara University of Science and Technology Faculty of Medicine

\section{Musa Kayondo}

Mbarara University of Science and Technology Faculty of Medicine

\section{Research Article}

Keywords: Pelvic organ prolapse, Uganda, Prevalence

Posted Date: August 10th, 2021

DOl: https://doi.org/10.21203/rs.3.rs-169939/v2

License: (9) This work is licensed under a Creative Commons Attribution 4.0 International License. Read Full License 


\section{Abstract}

\section{Purpose}

To determine the prevalence, clinical stage at presentation and factors associated with pelvic organ prolapse (POP) among women attending the gynecology outpatient clinic at Mbarara Regional Referral Hospital (MRRH), Uganda.

\section{Methods}

We conducted a cross sectional study at the gynecology outpatient clinic of MRRH from September 2019 to January 2020. Multiple logistic regression analysis was done to determine factors associated with pelvic organ prolapse.

Results

Of 338 participants enrolled, the prevalence of POP was $27.5 \%$ ( $n=93)$. POP stages were: stage $111.8 \%$ $(n=11)$, stage II $63.4 \%(n=59)$, stage III $16.1 \%(n=15)$ and stage IV $8.9 \%(n=8)$. Grand-multiparity (aOR 17.1, 95\% Cl: 1.1 - 66.6), birth weight more than 3.5kg (aOR 3.7, 95\% Cl: 1.1 - 12.6), perineal tears (aOR $6.5,95 \% \mathrm{Cl}: 2.1-20.2)$, peasant farmer (aOR 6.9, 95\% Cl: $1.6-29.9$ ) and duration of labour in the first delivery > 24 hours (aOR 5.7, 95\% Cl: $1.2-29$ ) were significantly associated with POP.

\section{Conclusion}

POP is common among women attending the gynecology clinic at MRRH with most of them presenting with stage II. There should be routine screening for POP to enable early identification and management especially in those who are grand multiparous, peasant farmers and history of perineal tears.

\section{Introduction}

Pelvic organ prolapse (POP) is the descent of any or all of the female pelvic organs (uterus, urinary bladder, urethra and rectum) through the vagina. It is characterized by descent of one or more of the anterior or posterior vaginal walls, the uterus or the vaginal vault (after a hysterectomy) (1). The global prevalence of pelvic organ prolapse in low income countries has been reported recently to be $2.9 \%$ $41.1 \%$ (2). In Sub-Saharan Africa, studies from Ghana, Gambia, Ethiopia and Tanzania have reported the prevalence of POP ranging from $12 \%-64.6 \%(3,4)$.

POP is a common distressing condition that occurs when there is a weakness in the supporting structures of the pelvic floor allowing the pelvic viscera to descend (5). Pelvic organ prolapse negatively affects a woman's quality of life by limiting physical, social, psychological and sexual function when in advanced stages. These consequences are more severe in women from low income countries than those in developed countries $(6,7)$. Pelvic organ prolapse is associated with various symptoms for example prolapse sensation, pelvic heaviness, vaginal pain, lower back pain, urinary incontinence and voiding 
dysfunction. These symptoms are important for healthcare professionals in decision making on whether to treat or not (5).

Staging process of POP with physical examination and diagnostic methods differ thus varying the prevalence of POP. In many studies, Baden-Walker Halfway and Women initiative staging systems have been used but lack reliability whereas pelvic organ prolapse quantification system (POP-Q) for staging pelvic organ prolapse has a higher intra-observer and inter-observer reliability (5).

A systematic review and meta-analysis of prevalence of, and risk factors for pelvic floor disorders in community - dwelling women in low and middle income countries, revealed that high parity, early marriage and child bearing were associated with POP (7). The Uganda Demographic and Health Survey done of 2016 showed that the fertility rate among Ugandan women was high at 5.8 with a median age of 18 years at first marriage (8). Although these factors are evident in rural southwestern Uganda, there is a paucity of information on the burden of POP and associated factors.

Therefore, this study set out to determine the prevalence, clinical stage at presentation and associated factors for pelvic organ prolapse among women attending gynaecology clinic at Mbarara Regional Referral Hospital, southwestern Uganda.

\section{Materials And Methods}

\section{Study population and setting}

We conducted a cross sectional study at the gynecology outpatient clinic of Mbarara Regional Referral Hospital (MRRH) from September 2019 to January 2020.

MRRH is a tertiary public health hospital providing services to a mixed urban-agrarian population southwestern Uganda and also serves as a teaching hospital for Mbarara University of Science and Technology. The gynecology outpatient clinic operates daily from Monday to Friday with an average daily attendance of 8 patients. MRRH has a pelvic floor surgeon who screens and manages women with pelvic organ prolapse.

We included all women 18 years and above who were attending the clinic. Pregnant women and those who had abnormal per vaginal bleeding and genital tumors were excluded from this study. Systematic random sampling of all women who met the inclusion criteria was performed to recruit the study participants using a sampling interval of 2 .

\section{Study procedure}

Information about the study, procedures and the nature of the questionnaire were explained to each participant. Baseline socio-demographic, medical, obstetric and gynecological histories were obtained using an interviewer guided questionnaire administered by the principal investigator and trained research assistants. Height, weight and blood pressure of the study participants were measured. 
Written informed consent was obtained from each participant.

Pelvic examination was performed for each of the study participants by the principal investigator to determine the presence of POP.

Staging of pelvic organ prolapse was done according to the Pelvic Organ Prolapse Quantification system (POP - Q) using a calibrated tongue depressor according to the standards set forth by the International Continence Society (9). The examination was performed while the patient was in lithotomy position using a Sims speculum after her urinary bladder had been emptied. The point of descent in relation to the hymen while performing valsalva manoeuvre was recorded as the stage in the three areas examined (anterior, posterior and apical). Stage I was point of descent of $1 \mathrm{~cm}$ above the level of the hymen. Stage II was point of descent within $1 \mathrm{~cm}$ above and below the level of the hymen. Stage III was a point of descent of more than $1 \mathrm{~cm}$ below the level of the hymen but didn't form a complete prolapse while stage IV was complete prolapse. The overall POP-Q stage was the POP-Q Stage of the most severely prolapsed compartment according to the POP-Q classification. Women with any stage of POP were considered to be having pelvic organ prolapse.

Every 10th case was reviewed by the pelvic floor surgeon to ensure quality control of POP-Q system clinical assessment.

\section{Study variables}

The dependent variable in this study was pelvic organ prolapse. Independent variables included the following; Socio-demographic characteristics (age of the participant, occupation, hours of heavy lifting of more than $10 \mathrm{~kg}$ per day, place of residence, level of education and income of the participant), obstetric factors (parity, prime para- those who have delivered once, multipara - between 2 and 4 deliveries and grand multipara- greater than or equal to 5 deliveries), mode of delivery, age at first delivery and place of first delivery, duration of overall labour at first delivery, perineal tears, inter delivery interval and heaviest birth weight (heaviest weight of baby the study participant had ever delivered), medical factors (body mass index, history of any of the following; diabetes mellitus, hypertension, chronic cough, and chronic constipation (history of less or equal to 3 bowel motions in a week or passing of hard stools for more than three months prior to presentation), and gynecological factors (prior history of hysterectomy).

\section{Sample size and statistical analysis}

We calculated the sample size using Kish and Leslie 1965 formula, based on the following assumptions: Confidence interval level of $95 \%$, required precision of the estimate of 0.05 , proportion of pelvic organ prolapse of $27.1 \%$ drawn from a cross sectional study done at Mersin Teaching Hospital, Turkey (10) and $10 \%$ non-response rate.

This gave us a total sample size of 338 participants.

Data was entered in Research Electronic Data Capture (RED cap) database and then exported to and analysed using computer software STATA 15 (Version 15.0, StataCorp, College Station, 224 TX). 
Prevalence of pelvic organ prolapse was calculated as a proportion of participants with POP out of the total number of study participants examined at gynecological outpatient during the study period and expressed as a percentage. The corresponding $95 \%$ confidence interval was also computed and reported.

The frequencies of the different clinical stages of pelvic organ prolapse were presented in a bar graph.

Participants' characteristics presented as categorical variables were compared between women with POP and those without POP subgroups using chi-square test, with the level of significance set at 0.05 .

We conducted univariate and multivariate logistic regression to determine the independent factors associated with POP. Univariate logistic regression analysis was conducted for demographic, obstetric, medical and gynecological factors. Unadjusted odds ratios, 95\% confidence intervals and $p$-values were reported. Factors with $p$-values less than 0.05 at univariate analysis were put into a multiple logistic regression analysis model. Adjusted odds ratios, $95 \%$ confidence intervals and $p$-values were reported. Factors with $p$-values less than 0.05 were considered to be statistically significant.

\section{Ethical consideration}

Ethical clearance was obtained from the Mbarara university research ethics committee (NO: 27/07-19) and the Uganda National Council for Science and Technology (HS706ES). Written informed consent was obtained from all the study participants.

\section{Results}

A total of 815 patients attended the gynecology outpatient during the study period. Of these, 408 were eligible to participate in the study. Seventy participants who had genital tumors, abnormal per vagina bleeding and positive urine HCG were excluded from the study. Therefore, 338 women were enrolled into the study and were screened for pelvic organ prolapse (POP). Of these $27.5 \%(n=93)$ had POP.

Majority of women with POP were between 34-49 years of age, peasant farmers, had attained primary education and were residing a distance of more $5 \mathrm{~km}$ from MRRH. This is shown in Table 1. 
Table 1

Baseline socio-demographic characteristics of the study participants

\begin{tabular}{|c|c|c|c|c|}
\hline Characteristics & Total & Prolapse $\mathrm{N}=93$ & No Prolapse N = 245 & p-value \\
\hline Maternal age & & & & $<0.001$ \\
\hline $18-33$ & $151(44.7)$ & $23(24.7)$ & $128(52.2)$ & \\
\hline $34-49$ & $125(37.0)$ & $39(41.9)$ & $86(35.1)$ & \\
\hline$\geq 50$ & $62(18.3)$ & 31 (33.3) & $31(12.7)$ & \\
\hline Marital status & & & & 0.053 \\
\hline Currently married & $268(79.3)$ & $69(74.2)$ & $199(81.2)$ & \\
\hline Cohabiting & $13(3.9)$ & $01(1.1)$ & $12(4.9)$ & \\
\hline Widowed & $34(10.1)$ & $14(15.0)$ & $20(8.2)$ & \\
\hline Separated & $23(6.8)$ & $09(9.7)$ & $14(5.7)$ & \\
\hline Highest level of Education & & & & $<0.001$ \\
\hline No formal education & $48(14.2)$ & $24(25.8)$ & $24(9.7)$ & \\
\hline Primary & $150(44.4)$ & $44(47.3)$ & $106(43.3)$ & \\
\hline Secondary & $90(26.6)$ & $21(22.6)$ & $69(28.2)$ & \\
\hline Tertiary & $50(14.8)$ & $04(4.3)$ & $46(18.8)$ & \\
\hline Occupation & & & & $<0.001$ \\
\hline Peasant farmer & $122(36.1)$ & $53(57.0)$ & $69(28.2)$ & \\
\hline Professional & $50(14.8)$ & $06(6.4)$ & $44(18.0)$ & \\
\hline Business & $78(23.1)$ & $22(23.7)$ & $56(22.8)$ & \\
\hline Unemployed & $88(26.0)$ & $12(12.9)$ & $76(31.0)$ & \\
\hline Income of the Participant * & & & & 0.263 \\
\hline Monthly income $<50,000$ UGX & $147(43.5)$ & $45(48.4)$ & $102(41.6)$ & \\
\hline Monthly income $\geq 50,000$ UGX & $191(56.5)$ & $48(51.6)$ & $143(58.4)$ & \\
\hline Distance from MRRH & & & & $<0.001$ \\
\hline$<5 \mathrm{Km}$ & $104(30.8)$ & $16(17.2)$ & $88(35.9)$ & \\
\hline$\geq 5 \mathrm{Km}$ & $234(69.2)$ & $77(82.8)$ & $157(64.1)$ & \\
\hline * Uganda Shillings & & & & \\
\hline
\end{tabular}


The prevalence of asymptomatic and symptomatic pelvic organ prolapse among women attending gynecology outpatient clinic of Mbarara Regional Referral Hospital was $27.5 \%(n=93)$ with $95 \%$ confidence interval of 23.0-32.5 as shown in Fig. 1.

Figure 1: Pie chart showing the prevalence of pelvic organ prolapse $(\mathrm{N}=338)$

Majority of the women with pelvic organ prolapse at gynecology outpatient clinic of MRRH presented with stage II 63.3\% $(n=59)$ as shown in Fig. 2.

Figure 2: Clinical Pelvic Organ Prolapse Stage at presentation of women attending gynecology outpatient clinic of MRRH ( $\mathrm{N}=93)$

Increasing age, low education level, occupation, and distance from MRRH, heavy lifting and history of chronic constipation were significantly associated with pelvic organ prolapse as shown in Table 2. At multivariate analysis only occupation was independently associated with pelvic organ prolapse. 
Table 2

Univariate and multivariate analysis of socio-demographic, gynaecological and medical factors associated with pelvic organ prolapse.

\begin{tabular}{|c|c|c|c|c|c|c|}
\hline Characteristics & $\begin{array}{l}\text { Prolapse N } \\
=93\end{array}$ & $\begin{array}{l}\text { No Prolapse N } \\
=245\end{array}$ & $\operatorname{cOR}(95 \% \mathrm{Cl})$ & $\begin{array}{l}\mathrm{p}- \\
\text { value }\end{array}$ & $\begin{array}{l}\mathrm{aOR}(95 \% \\
\mathrm{Cl})\end{array}$ & $\begin{array}{l}\text { p- } \\
\text { value }\end{array}$ \\
\hline \multicolumn{7}{|l|}{ Maternal age } \\
\hline $18-33$ & $23(24.7)$ & $128(52.2)$ & Ref & & Ref & \\
\hline $34-49$ & $39(41.9)$ & $86(35.1)$ & $\begin{array}{l}2.5(1.4- \\
4.5)\end{array}$ & 0.002 & $\begin{array}{l}0.4(0.1- \\
1.5)\end{array}$ & 0.163 \\
\hline$\geq 50$ & 31 (33.3) & $31(12.7)$ & $\begin{array}{l}5.6(2.9- \\
10.8)\end{array}$ & $<.001$ & $\begin{array}{l}0.4(0.3- \\
2.3)\end{array}$ & 0.305 \\
\hline \multicolumn{7}{|l|}{$\begin{array}{l}\text { Highest level of } \\
\text { Education }\end{array}$} \\
\hline Tertiary & $04(4.3)$ & $46(18.8)$ & Ref & & Ref & \\
\hline Secondary & $21(22.6)$ & $69(28.2)$ & $\begin{array}{l}3.5(1.1- \\
10.9)\end{array}$ & 0.030 & $\begin{array}{l}3.0(0.4- \\
25.9)\end{array}$ & 0.310 \\
\hline Primary & 44 (47.3) & $106(43.3)$ & $\begin{array}{l}4.8(1.6- \\
14.1)\end{array}$ & 0.005 & $\begin{array}{l}1.5(0.1- \\
16.6)\end{array}$ & 0.736 \\
\hline No formal education & $24(25.8)$ & $24(9.7)$ & $\begin{array}{l}11.5(3.6- \\
37.0)\end{array}$ & $<.001$ & $\begin{array}{l}0.3(0.0- \\
7.9)\end{array}$ & 0.459 \\
\hline \multicolumn{7}{|l|}{ Occupation } \\
\hline Unemployed & $12(12.9)$ & 76 (31.0) & Ref & & Ref & \\
\hline Business & $22(23.7)$ & $56(22.9)$ & $\begin{array}{l}2.5(1.1- \\
5.4)\end{array}$ & 0.023 & $\begin{array}{l}3.1(0.4- \\
25.7)\end{array}$ & 0.301 \\
\hline Professional & $06(6.5)$ & $44(18.0)$ & $\begin{array}{l}0.9(0.3- \\
2.5)\end{array}$ & 0.784 & $\begin{array}{l}1.6(0.3- \\
9.1)\end{array}$ & 0.589 \\
\hline Peasant farmer & $53(57.0)$ & $69(28.1)$ & $\begin{array}{l}4.9(2.4- \\
9.9)\end{array}$ & $<.001$ & $\begin{array}{l}6.9(1.6- \\
9.9)\end{array}$ & 0.010 \\
\hline \multicolumn{7}{|l|}{$\begin{array}{l}\text { Income of the } \\
\text { Participant }\end{array}$} \\
\hline $\begin{array}{l}\text { Monthly income }< \\
50.000=\end{array}$ & 45 (48.4) & $102(41.6)$ & Ref & & & \\
\hline $\begin{array}{l}\text { Monthly income }< \\
50.000=\end{array}$ & $48(51.6)$ & $143(58.4)$ & $\begin{array}{l}0.8(0.3- \\
1.2)\end{array}$ & 0.264 & & \\
\hline \multicolumn{7}{|l|}{ Distance from MRRH } \\
\hline$<5 \mathrm{Km}$ & $16(17.2)$ & 88 (35.9) & Ref & & Ref & \\
\hline
\end{tabular}




\begin{tabular}{|c|c|c|c|c|c|c|}
\hline Characteristics & $\begin{array}{l}\text { Prolapse N } \\
=93\end{array}$ & $\begin{array}{l}\text { No Prolapse N } \\
=245\end{array}$ & cOR(95\%Cl) & $\begin{array}{l}\mathrm{p}- \\
\text { value }\end{array}$ & $\begin{array}{l}\mathrm{aOR}(95 \% \\
\mathrm{Cl})\end{array}$ & $\begin{array}{l}\mathrm{p}- \\
\text { value }\end{array}$ \\
\hline$>5 \mathrm{Km}$ & 77 (82.8) & $157(64.1)$ & $\begin{array}{l}2.7(1.5- \\
4.9)\end{array}$ & 0.001 & $\begin{array}{l}3.8(0.6- \\
21.9)\end{array}$ & 0.140 \\
\hline \multicolumn{7}{|c|}{ Chronic constipation } \\
\hline No & $81(87.1)$ & $239(97.6)$ & Ref & & Ref & \\
\hline Yes & $12(12.9)$ & $06(2.4)$ & $\begin{array}{l}5.9(2.1- \\
16.2)\end{array}$ & 0.001 & $\begin{array}{l}8.3(1.0 \\
-72.1)\end{array}$ & 0.054 \\
\hline \multicolumn{7}{|c|}{$\begin{array}{l}\text { Heavy lifting in hours } \\
\text { per day }\end{array}$} \\
\hline $0-1$ & $32(34.4)$ & $152(62.0)$ & Ref & & Ref & \\
\hline $2-4$ & $17(18.3)$ & $54(22.0)$ & $\begin{array}{l}1.5(0.8- \\
2.9)\end{array}$ & 0.236 & $\begin{array}{l}0.9(0.2- \\
4.6)\end{array}$ & 0.920 \\
\hline 5 and above & $44(47.3)$ & 39 (16.0) & $\begin{array}{l}5.4(3.0- \\
9.5)\end{array}$ & $<.001$ & $\begin{array}{l}4.0(0.7- \\
21.1)\end{array}$ & 0.106 \\
\hline \multicolumn{7}{|c|}{$\begin{array}{l}\text { Body mass index in } \\
\mathrm{Kg} / \mathrm{m}^{2}\end{array}$} \\
\hline Below 25 & $54(58.1)$ & $120(49)$ & Ref & & & \\
\hline $25-29.9$ & $23(24.7)$ & $73(29.8)$ & $\begin{array}{l}0.7(0.4- \\
1.2)\end{array}$ & 0.219 & & \\
\hline 30 and above & $16(17.2)$ & $52(21.2)$ & $\begin{array}{l}0.7(0.4- \\
1.3)\end{array}$ & 0.249 & & \\
\hline
\end{tabular}

At univariate analysis, parity, age at first delivery, place of delivery, mode of delivery, duration of labour in the first delivery, perineal tears, heaviest birth weight of babies and inter birth interval were significantly associated with pelvic organ prolapse as shown in Table 3. At multivariate analysis only parity, duration of labour in the first delivery, heaviest birth weight of babies and perineal tears were independently associated with pelvic organ prolapse. 
Table 3

Univariate and multivariate analysis of obstetric factors associated with pelvic organ prolapse.

\begin{tabular}{|c|c|c|c|c|c|c|}
\hline Variables & $\begin{array}{l}\text { Prolapse n } \\
=93(\%)\end{array}$ & $\begin{array}{l}\text { No prolapse } \mathrm{n} \\
=245(\%)\end{array}$ & $\begin{array}{l}\text { cOR } \\
(95 \% \mathrm{Cl})\end{array}$ & $\begin{array}{l}\mathrm{p}- \\
\text { value }\end{array}$ & $\begin{array}{l}\text { aOR } \\
(95 \% \mathrm{Cl})\end{array}$ & $\begin{array}{l}\mathrm{p}- \\
\text { value }\end{array}$ \\
\hline \multicolumn{7}{|l|}{ Parity $(n=338)$} \\
\hline 1 & $08(8.6)$ & $84(34.3)$ & Ref & & Ref & \\
\hline $2-4$ & $33(35.5)$ & $100(40.8)$ & $\begin{array}{l}3.5 \\
(1.5- \\
7.9)\end{array}$ & 0.003 & $\begin{array}{l}4.3(0.4- \\
18.1)\end{array}$ & 0.234 \\
\hline$\geq 5$ & $52(55.9)$ & $61(24.9)$ & $\begin{array}{l}9.0 \\
(3.9- \\
20.2)\end{array}$ & $<.001$ & $\begin{array}{l}17.1 \\
(1.1- \\
66.6)\end{array}$ & 0.043 \\
\hline \multicolumn{7}{|l|}{$\begin{array}{l}\text { Age at first delivery ( } n= \\
338 \text { ) }\end{array}$} \\
\hline $20-29$ & $38(40.9)$ & $128(52.2)$ & Ref & & Ref & \\
\hline$<20$ & $54(58.1)$ & $106(43.3)$ & $\begin{array}{l}1.7 \\
(1.1- \\
2.8)\end{array}$ & 0.030 & $\begin{array}{l}0.5(0.0- \\
12.0)\end{array}$ & 0.689 \\
\hline$\geq 30$ & $01(1.0)$ & $11(4.5)$ & $\begin{array}{l}0.3 \\
(0.0- \\
2.4)\end{array}$ & 0.265 & $\begin{array}{l}0.8(0.0- \\
20.4)\end{array}$ & 0.899 \\
\hline \multicolumn{7}{|l|}{$\begin{array}{l}\text { Place of first delivery ( } \mathrm{n} \\
=338 \text { ) }\end{array}$} \\
\hline Health facility & $41(44.1)$ & $201(82.0)$ & Ref & & Ref & \\
\hline Home delivery & $52(55.9)$ & $44(18.0)$ & $\begin{array}{l}5.8 \\
(3.4- \\
9.8)\end{array}$ & $<.001$ & $\begin{array}{l}0.1(0.0- \\
1.3)\end{array}$ & 0.074 \\
\hline \multicolumn{7}{|l|}{$\begin{array}{l}\text { Mode of delivery }(n= \\
338)\end{array}$} \\
\hline Caesarian section & $03(3.2)$ & $57(23.3)$ & Ref & & Ref & \\
\hline Vaginal delivery & $90(96.8)$ & $188(76.7)$ & $\begin{array}{l}9.1 \\
(2.8- \\
29.8)\end{array}$ & $\dot{0} 001$ & $\begin{array}{l}1.4(0.3- \\
8.0)\end{array}$ & 0.678 \\
\hline \multicolumn{7}{|l|}{$\begin{array}{l}\text { Vaginal delivery }(n= \\
281)\end{array}$} \\
\hline $\begin{array}{l}\text { Spontaneous Vaginal } \\
\text { delivery }\end{array}$ & $86(94.5)$ & $183(96.3)$ & Ref & & & \\
\hline
\end{tabular}

* Statistically significant $p<0.05$, Ref - Reference group 


\begin{tabular}{|c|c|c|c|c|c|c|}
\hline Variables & $\begin{array}{l}\text { Prolapse } n \\
=93(\%)\end{array}$ & $\begin{array}{l}\text { No prolapse } n \\
=245(\%)\end{array}$ & $\begin{array}{l}\text { cOR } \\
(95 \% \mathrm{Cl})\end{array}$ & $\begin{array}{l}p- \\
\text { value }\end{array}$ & $\begin{array}{l}\text { aOR } \\
(95 \% \mathrm{Cl})\end{array}$ & $\begin{array}{l}\mathrm{p} \text { - } \\
\text { value }\end{array}$ \\
\hline Vacuum extraction & $05(5.5)$ & $07(3.7)$ & $\begin{array}{l}1.5 \\
(0.5- \\
4.9)\end{array}$ & 0.485 & & \\
\hline \multicolumn{7}{|l|}{$\begin{array}{l}\text { Duration of labour at } \\
\text { the first delivery }\end{array}$} \\
\hline$<24$ hours & $50(53.8)$ & $17(72.6)$ & Ref & & Ref & \\
\hline$\geq 24$ hours & $43(45.2)$ & $67(27.4)$ & $\begin{array}{l}2.2 \\
(1.4- \\
3.7)\end{array}$ & 0.002 & $\begin{array}{l}3.9(1.3- \\
6.5)\end{array}$ & 0.012 \\
\hline \multicolumn{7}{|c|}{$\begin{array}{l}\text { Heaviest birth weight ( } \mathrm{n} \\
=338 \text { ) }\end{array}$} \\
\hline$<3.5 \mathrm{Kg}$ & $08(18.6)$ & $97(47.1)$ & Ref & & Ref & \\
\hline$\geq 3.5 \mathrm{Kg}$ & $35(81.4)$ & $109(52.9)$ & $\begin{array}{l}3.9 \\
(1.7- \\
8.8)\end{array}$ & 0.001 & $\begin{array}{l}3.7(1.1- \\
12.6)\end{array}$ & 0.034 \\
\hline \multicolumn{7}{|c|}{ Perineal tears $(n=338)$} \\
\hline No & $56(60.2)$ & $210(85.7)$ & Ref & & Ref & \\
\hline Yes & $37(39.8)$ & $35(14.3)$ & $\begin{array}{l}4.0 \\
(2.4- \\
6.9)\end{array}$ & $<001$ & $\begin{array}{l}6.5(2.1- \\
20.2)\end{array}$ & 0.001 \\
\hline \multicolumn{7}{|l|}{$\begin{array}{l}\text { Average Interdelivery } \\
\text { interval in years }\end{array}$} \\
\hline$\geq 2$ years & $20(23.3)$ & 73 (39.3) & Ref & & Ref & \\
\hline$<2$ years & $66(76.7)$ & $113(60.7)$ & $\begin{array}{l}2.1 \\
(1.2- \\
3.8)\end{array}$ & 0.011 & $\begin{array}{l}1.6(0.5- \\
4.6)\end{array}$ & 0.413 \\
\hline
\end{tabular}

\section{Discussion}

The prevalence of Pelvic organ prolapse at Mbarara Regional Referral Hospital (MRRH) was 27.5\% (95\% Cl: $23.0 \%-32.5 \%)$ while the commonest stage of pelvic organ prolapse was stage II (63.4\%) and the factors independently associated with POP in our study were grand multiparity, perineal tears, duration of overall labour in the first delivery more than 24 hours, heaviest birth weight of $\geq 3.5 \mathrm{~kg}$ and being a peasant farmer. 
The prevalence of POP at MRRH compares with that in a hospital based study at Mersin teaching hospital, Turkey among women attending gynecology clinic which was $27.1 \%$ (10). This study included both asymptomatic and symptomatic Pelvic Organ Prolapse patients similar to what was done in our setting. It is however, higher than that of a retrospective study done at Usmanu Danfodiyo University teaching Hospital, Sokoto Nigeria which was $1.4 \%$ (11). The difference is probably because in our study we considered women attending the gynecology outpatient clinic while in Nigeria they studied women who had been admitted with symptomatic pelvic organ Prolapse. The prevalence of POP at MRRH was lower than that of a community based study done in Kilimanjaro Tanzania (64.5\%) (4). This is possibly because the population based study in Tanzania involved an older population and symptomatic women with a high prevalence of POP. The median age of the study done in Tanzania was 46 years whereas the median age of our study was 38 years with the same age range of 18-90 years.

In a study done in the United States of America, the prevalence of POP was lower in African American women $1.9 \%$ as compared to White women $2.8 \%$ and Hispanic women $5.1 \%(12)$. This when compared with our study suggests a high disparity in the prevalence of POP between the high income and the low income countries.

The commonest stage of pelvic organ prolapse among the study participants at MRRH was stage II. This compares with a community based study done in Kilimanjaro Tanzania where $63.6 \%$ of study participants with POP had stage II (4). However, our study differs with the study done in Nepal where the commonest POP stage at presentation was stage III. This is because the study participants in the study done in Nepal were admitted patients with advanced pelvic organ prolapse for surgery (13). These findings emphasize the need to have affordable interventions to manage women with early stage POP in low income countries.

The findings from our study show that grand multiparity, perineal tears, heaviest birth weight more than $3.5 \mathrm{~kg}$, duration of labour more than 24 hours and being a peasant farmer are associated with pelvic organ prolapse.

We found that grand multiparity was associated with Pelvic organ prolapse. Our findings are in agreement with the previous studies done in Gambia and Tanzania where women who had eight or more deliveries had 15 times risk of POP compared to nulliparous $(4,14)$. The increasing number of deliveries suggests incremental pelvic organ support disruption including levator ani damage, endopelvic fascial injury and nerve damage.

Our study also found that perineal tears were associated with pelvic organ prolapse in our setting. Similar findings were obtained in a case control study done in two tertiary hospitals in North West Ethiopia (15). Perineal tears are clinical markers for levator ani muscle trauma, perineal body damage resulting in widening of the genital hiatus which is associated with anterior and central compartment prolapse (16). These findings emphasize the need for routine support of the perineum during delivery to prevent perineal tears (17). 
We found that women who delivered a heavier birth weight of more than $3.5 \mathrm{~kg}$ were four times likely to have pelvic organ prolapse. Risk of pelvic organ prolapse increases with increasing birth weight of babies delivered vaginally. This study finding compares with the study in Turkey where mean birth weight of babies of women with POP was significantly higher than those without POP (3584 \pm 574 Vs $3490 \pm 389$ g) p-value 0.004 (10). Vaginal delivery to big babies is a major risk factor for levator ani trauma. The heavier the baby is, the bigger presenting diameter, the more the stretch injury or nerve compression damage for the pelvic diaphragm thus eventual pelvic organ prolapse.

Duration of labour in the first delivery more than 24 hours was strongly associated with pelvic organ prolapse in our setting. Women whose duration of labour in the first delivery was more than 24 hours were 3.9 times likely to have POP. This is in concordance with findings from studies done in developing countries (Tanzania, Ethiopia and Ghana) which documented that women who had experienced prolonged labour in first delivery had almost two times increased risk of pelvic organ prolapse development $(4,18,19)$. Prolonged labour in the first delivery and difficult labour at home and even sometimes at the health facility all contribute significantly to pelvic floor damage and pelvic organ prolapse in the long term.

We also found that women who were peasant farmers were more likely to have pelvic organ prolapse. This finding is in agreement with other studies done in Tanzania and Nepal, where women involved in farming had almost four times increased risk of severe POP development (aOR 3.5 Cl: 1.2-9.6) $(4,20)$. Farming activities are physically demanding day to day activities that increase intra-abdominal pressure thus more stretch to the pelvic diaphragm predisposing to pelvic organ prolapse (21).

However our study had some limitations. First, this was a study conducted at a single regional referral hospital and might not be generalizable across all regional referral hospitals in southwestern Uganda. Secondly, the obstetric factors examined in this study were self-reported and might have resulted into recall bias.

\section{Conclusion}

The prevalence of Pelvic organ prolapse among women attending the gynecological outpatient clinic is high. The commonest stage of POP at presentation is stage II and grandmultiparity, perineal tears, heaviest birth weight of $\geq 3.5 \mathrm{~kg}$, duration of labour in the first delivery more than 24 hours and being a peasant farmer are significantly associated with pelvic organ prolapse.

Clinicians should routinely screen women (grand multiparas and those with perineal tears) attending the gynecology clinic for Pelvic organ prolapse because it is common. Prevention measures like routine support of the perineum during vaginal delivery to prevent POP as well as pelvic floor exercises and pessaries to prevent early stage POP from progressing to advanced stages should be emphasized.

\section{Declarations}




\section{Conflict of Interest: The authors declared no conflict of interest in this work. Ethical Approval: Ethical clearance was obtained from the Mbarara university research ethics committee (NO: 27/07-19) and the Uganda National Council for Science and Technology (HS706ES).}

\section{Consent to participate and for publication: Written informed consent was obtained from all the study participants.}

Availability of Data and Material: Data available on request

Author contributions: T Rodgers, K Musa, K Hamson, M Sezalio, KK Paul, K Rogers were involved in initial project development and planning. T Rodgers was involved in data collection. LM Henry, T Rodgers, KK Paul and $\mathrm{K}$ Rogers were involved in the data analysis and writing up and editing of the manuscript. $\mathrm{K}$ Musa and M Sezalio were involved in the supervision of this research work. All authors read and approved the final manuscript.

Acknowledgements: The authors are grateful to the research assistants Dr Ahabwe Onesmus, Dr Asiimwe Fiona. We acknowledge the staff at the gynaecology outpatient clinic of Mbarara Regional Referral hospital and all the study participants.

Code availability: Not applicable

\section{References}

1. Barber MD. Pelvic organ prolapse. Bmj. 2016;354.

2. Yuk JS, Lee JH, Hur JY, Shin JH. The prevalence and treatment pattern of clinically diagnosed pelvic organ prolapse: a Korean National Health Insurance Database-based cross-sectional study 20092015. Sci Rep. 2018;8(1):018-19692.

3. Akmel M, Segni H. Pelvic organ prolapse in jimma university specialized hospital, southwest ethiopia. Ethiopian journal of health sciences. 2012;22(2):85-92.

4. Masenga GG, Shayo BC, Rasch V. Prevalence and risk factors for pelvic organ prolapse in Kilimanjaro, Tanzania: A population based study in Tanzanian rural community. PLoS One. 2018;13(4). 
5. Persu C, Chapple CR, Cauni V, Gutue S, Geavlete P. Pelvic Organ Prolapse Quantification System (POP-Q) - a new era in pelvic prolapse staging. Journal of medicine and life. 2011;4(1):75-81.

6. Wusu-Ansah OK, Opare-Addo HS. Pelvic organ prolapse in rural Ghana. Int J Gynaecol Obstet. 2008;103(2):121-4.

7. Islam RM, Oldroyd J, Karim MN, Hossain SM, Md Emdadul Hoque D, Romero L, et al. Systematic review and meta-analysis of prevalence of, and risk factors for, pelvic floor disorders in communitydwelling women in low and middle-income countries: a protocol study. BMJ Open. 2017;7(6):2016015626.

8. Uganda Bureau of Statistics I. Uganda demographic and health survey 2016: key indicators report. UBOS, and Rockville Maryland; 2017.

9. Bump RC, Mattiasson A, Bø K, Brubaker LP, DeLancey JO, Klarskov P, et al. The standardization of terminology of female pelvic organ prolapse and pelvic floor dysfunction. American journal of obstetrics and gynecology. 1996;175(1):10-7.

10. Aytan $\mathrm{H}$, Ertunc D, Tok EC, Yasa O, Nazik H. Prevalence of pelvic organ prolapse and related factors in a general female population. Turk J Obstet Gynecol. 2014;11(3):176-80.

11. Yakubu A, Panti A, Ladan A, Burodo A, Hassan M, Nasir S. Pelvic organ prolapse managed at Usmanu Danfodiyo University Teaching Hospital, Sokoto: A 10-year review. Sahel Medical Journal. 2017;20(1):26-9.

12. Nygaard I, Barber MD, Burgio KL, Kenton K, Meikle S, Schaffer J, et al. Prevalence of symptomatic pelvic floor disorders in US women. Jama. 2008;300(11):1311-6.

13. Bodner-Adler B, Shrivastava C, Bodner K. Risk factors for uterine prolapse in Nepal. Int Urogynecol J Pelvic Floor Dysfunct. 2007;18(11):1343-6.

14. Scherf C, Morison L, Fiander A, Ekpo G, Walraven G. Epidemiology of pelvic organ prolapse in rural Gambia, West Africa. BJOG: An International Journal of Obstetrics \& Gynaecology. 2002;109(4):431-6.

15. Asresie A, Admassu E, Setegn T. Determinants of pelvic organ prolapse among gynecologic patients in Bahir Dar, North West Ethiopia: a case-control study. International journal of women's health. 2016;8:713-9.

16. Shek KL, Green K, Hall J, Guzman-Rojas R, Dietz HP. Perineal and vaginal tears are clinical markers for occult levator ani trauma: a retrospective observational study. Ultrasound in Obstetrics \& Gynecology. 2016;47(2):224-7.

17. Ali M, Migisha R, Ngonzi J, Muhumuza J, Mayanja R, Joe Lapat J, et al. Risk Factors for Obstetric Anal Sphincter Injuries among Women Delivering at a Tertiary Hospital in Southwestern Uganda. Obstet 
Gynecol Int [Internet]. 2020 2020; 2020:[6035974 p.]. Available

from: http://europepmc.org/abstract/MED/32508928

https://doi.org/10.1155/2020/6035974

https://europepmc.org/articles/PMC7244954

https://europepmc.org/articles/PMC7244954?pdf=render.

18. Megabiaw B, Adefris M, Rortveit G, Degu G, Muleta M, Blystad A, et al. Pelvic floor disorders among women in Dabat district, northwest Ethiopia: a pilot study. Int Urogynecol J. 2013;24(7):1135-43.

19. Walker GJ, Gunasekera P. Pelvic organ prolapse and incontinence in developing countries: review of prevalence and risk factors. Int Urogynecol J. 2011;22(2):127-35.

20. Khadgi J, Poudel A. Uterine prolapse: a hidden tragedy of women in rural Nepal. Int Urogynecol J. 2018;29(11):1575-8.

21. Babayi M, Azghani M-R, Hajebrahimi S, Berghmans B. Three-dimensional finite element analysis of the pelvic organ prolapse: A parametric biomechanical modeling. Neurourology and Urodynamics. 2019;38(2):591-8.

Figures 


\section{Pie chart showing the prevalence of Pelvic Organ Prolapse among women attending gynaecological outpatient clinic}

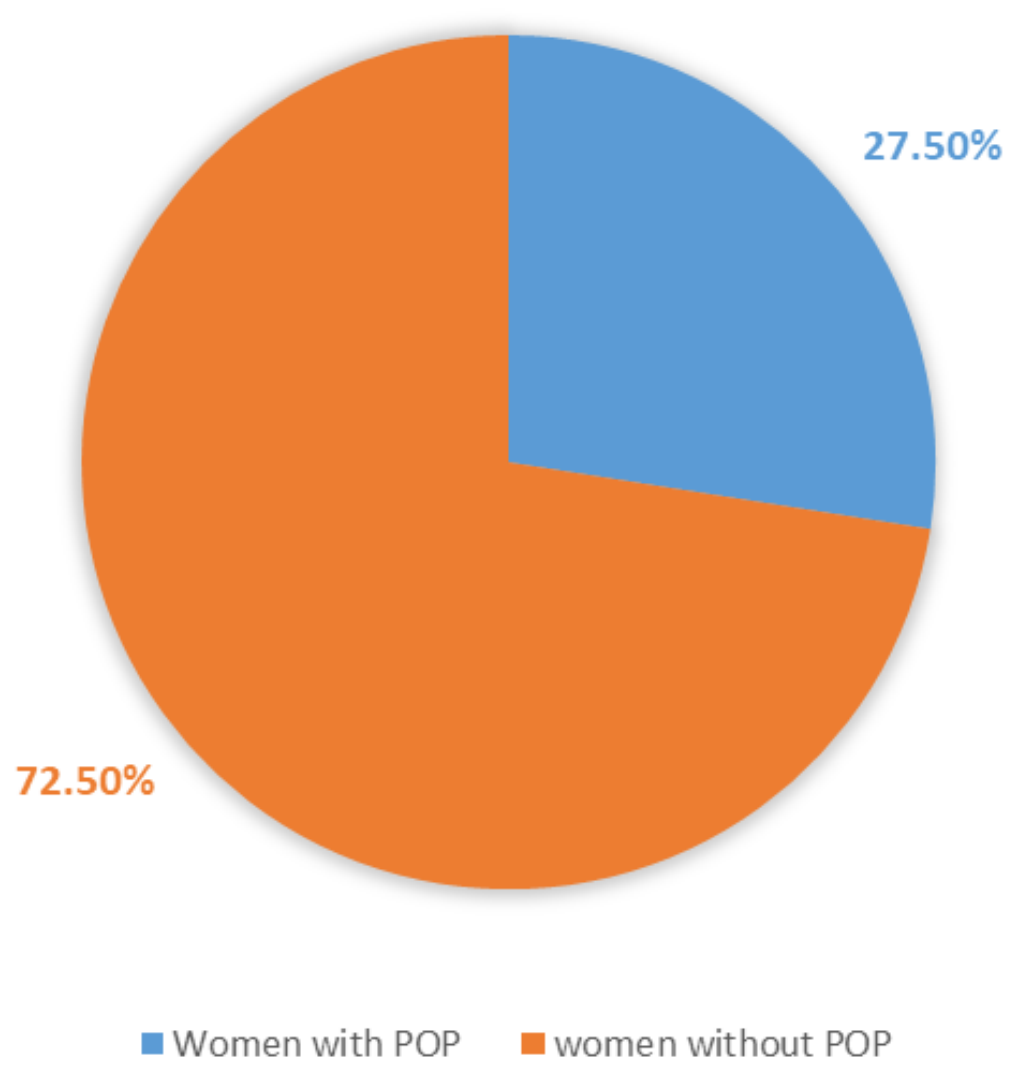

\section{Figure 1}

The prevalence of Pelvic Organ Prolapse among women attending gynaecological outpatient clinic of Mbarara Regional Referral Hospital 
Bar graph showing clinical stage of pelvic organ prolapse at presentation

$70.00 \%$

$63.40 \%$

$60.00 \%$

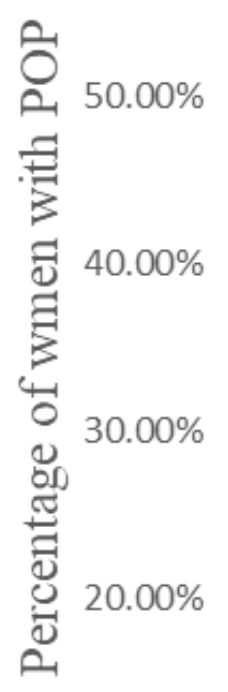

$10.00 \%$

$11.80 \%$

$0.00 \%$

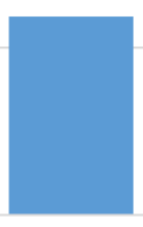

Stage I
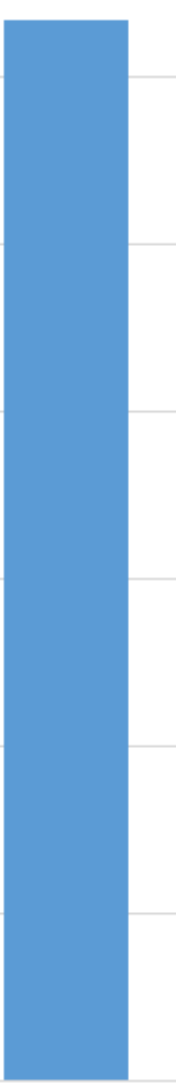

$16.10 \%$

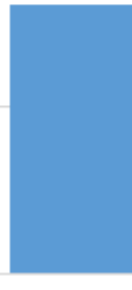

$8.60 \%$

Stage II

Stage III

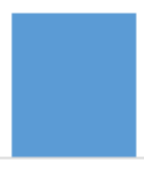

Stage IV

Clinical stage of POP at presentation

women with POP

\section{Figure 2}

Clinical Pelvic Organ Prolapse Stage at presentation of women attending gynecology outpatient clinic of MRRH ( $=93)$ 